\title{
Some remarkable experiments of Leonardo da Vinci
}

\author{
Enzo Macagno \\ Iowa Institute of Hydraulic Research \\ The University of Iowa \\ Iowa City, Iowa, USA
}

\section{Introductory comments}

Leonardo da Vinci left a fruitful heritage in the form of notebooks and loose sheets full of notes and drawings on a great variety of topics. Although unfortunately an important part of them is lost, some hope is left, however, after two valuable notebooks were found in the Biblioteca Nacional de Madrid less than three decades ago [Reti 1975]. Most of the fluid-mechanical content of Leonardo's notebooks, including those which have been known to exist for centuries, has been overlooked for a long time. Only a few studies exist, by hydraulicians and aerodynamicists, who have dealt with the original writings and not with anthologies; however, even the studies of the originals have not been, until very recently, really exhaustive. Among those which are good models for further research, we must include the papers on aeronautics by Giacomelli in the thirties and those on hydraulics by Arredi in the forties. We must take into account that, in the history of the science of flow, Leonardo is the first true researcher. Among his many works as artist, engineer, and scientist, those concerned with fluids properties, flow, and transport phenomena are surely the most original [Macagno $1985 \mathrm{~b}, 1987 \mathrm{a}$ ]. In all other fields we can find predecessors and contemporaries who could have taught him, or competed with him; not so in fluid mechanics, which was almost undeveloped and neglected, with very little correct results to offer, outside Archimedean hydrostatics.

It must not be forgotten that the fluid-mechanical knowledge attained by Leonardo is mainly qualitative, although he obtained some remarkable quantitative results, as in the cases of the conservation of volume and the law of what we call now irrotational vortex [Truesdell 1967, Macagno M. 1975]. I do not mean that one should belittle qualitative knowledge, because it is as valuable as the quantitative [Macagno 1953], and surely more precious in times of creation of a new science or a new discipline. Leonardo studied an immense variety of flows, comprising the flow of water, air, gases and vapor, combustion gases, mud, blood, sap, and also granular materials. In the respective notes we find a mixture of hit and misses, but what counts is a novel and fresh approach to flow phenomena which is, in many aspects, a pre-view of developments that came only in following centuries. Many very important aspects of Leonardo's flow science remain to be investigated fully by modern methods based in present knowledge of theoretical and experimental fluid mechanics [Macagno 1982, 1987a].
Leonardo's experiments make sense only if one has general notions of his main achievements in the corresponding field. Among his accomplishments in fluid mechanics, we can count the remarkable grasp of what we call now Lagrangian and Eulerian descriptions of fluid flow [Macagno 1991]. The Lagrangian point of view in Leonardo has so far been overlooked by all students of Leonardo's manuscripts, in spite of its being quite obvious, especially in many of his drawings; this may be due not only to the lack of knowledge of fluid mechanics by many who have written on Leonardo's studies of flow [see, e.g. Pedretti 1985 ], but also to the almost exclusive use of the Eulerian description by most hydraulicians and fluid-mechanicists until very recent times. Leonardo was also able to develop some understanding of what we designate as conservation principles, or postulates. Such understanding was notably keen in the case of conservation of volume, and less so for mass, momentum, and energy conservation. Another important achievement is that he showed a remarkable understanding of resistive forces and of what we would call today dissipation of energy or entropy.

Leonardo certainly had his own methodology in science and engineering, as he possessed it in art, a field in which he was perhaps more explicit about his approach. He knew that it was a long struggle before achieving the desired drawing or painting, and so he referred to his method as "componimento oscuro " [Gombrich 1966]. That he, as many others, may not have been completely aware of, and even mistaken about what was his own methodology, does not at all mean that it did not exist [Macagno $198 \mathrm{sb}$ ]. For many questions, he extensively and cleverly used analogical thinking in his investigations, although he was sometimes misled by analogy, which may be a deceptive approach unless carefully investigated [Macagno 1986a]. He also made great use of observation and experimentation, as is popularly believed although without the justification of a thorough study in the original documents of how the really proceeded in this area [Macagno 1989]. Naturally, he used trial and error approaches, as universally done by all experimentalists. In addition, he used paradoxes to a certain extent. To appreciate the role of paradoxes in Leonardian fluid mechanics, one must be well aware of the important role they have played, and still play, in hydromechanics [Birkhoff 1950$]$.

I have studied previously some of the experiments I describe in this paper, but they need some re-interpretation in the light of my recent additional investigation of Leonardo's notes and drawings. Only a few experiments will be considered here, but they cover a wide range of situations. In

LA HOUILLE BLANCHE/N 6-1991 
1.

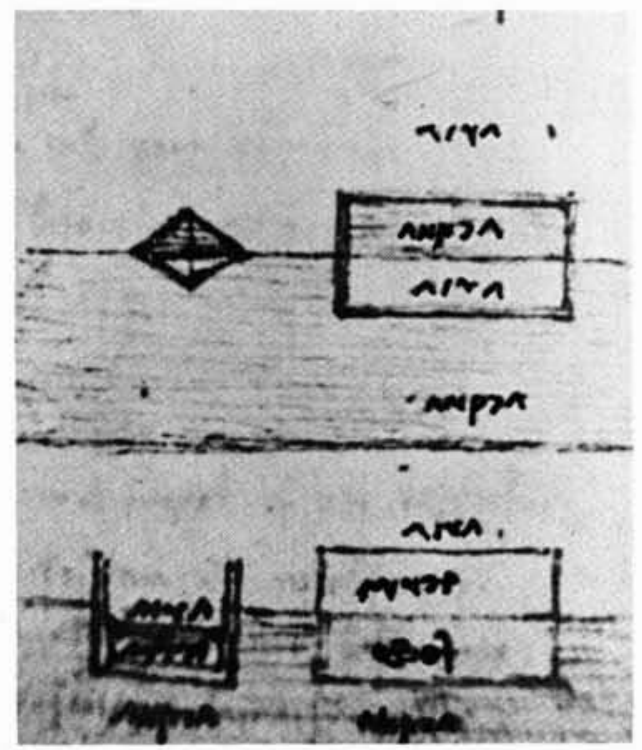

4.
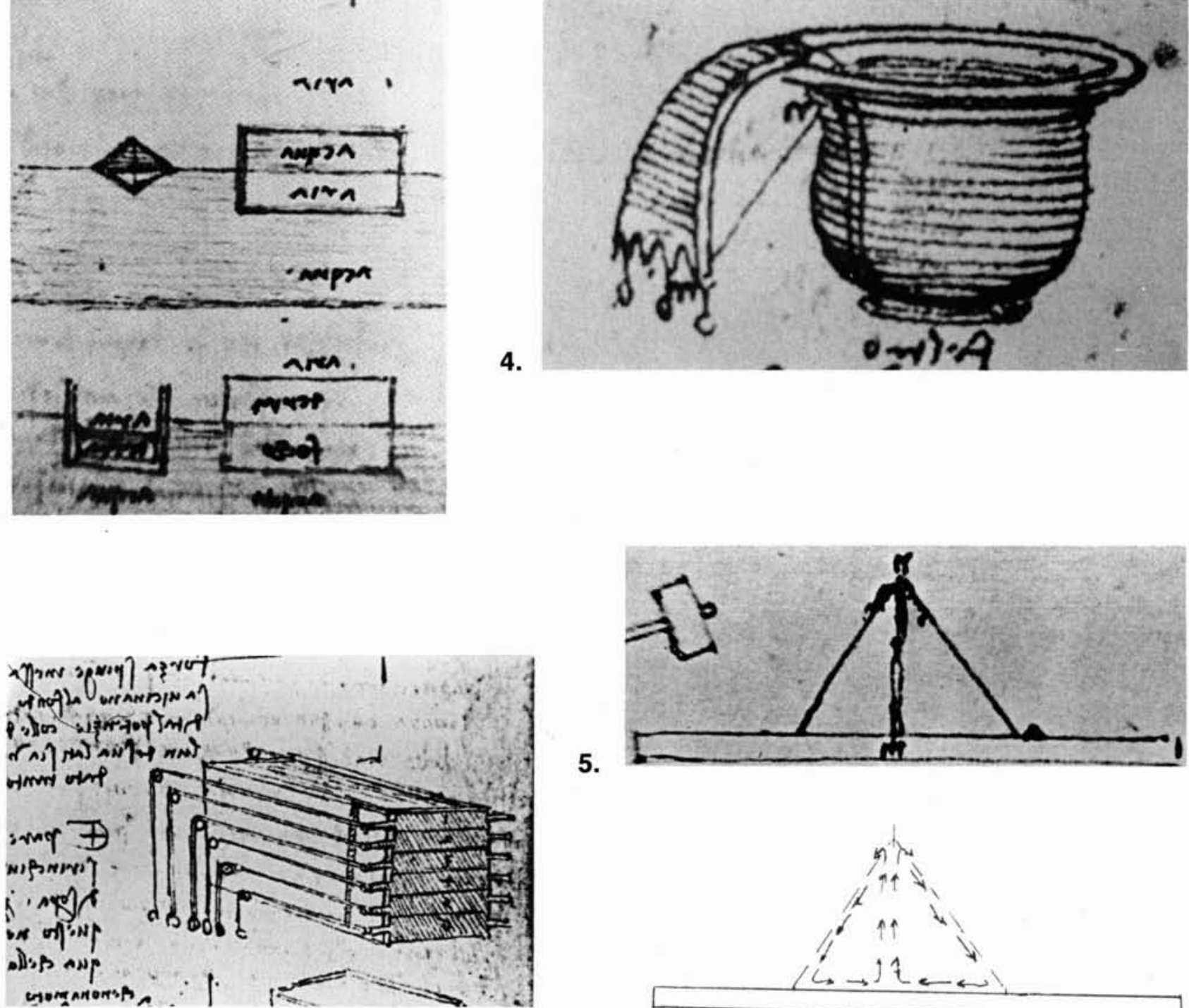

5.
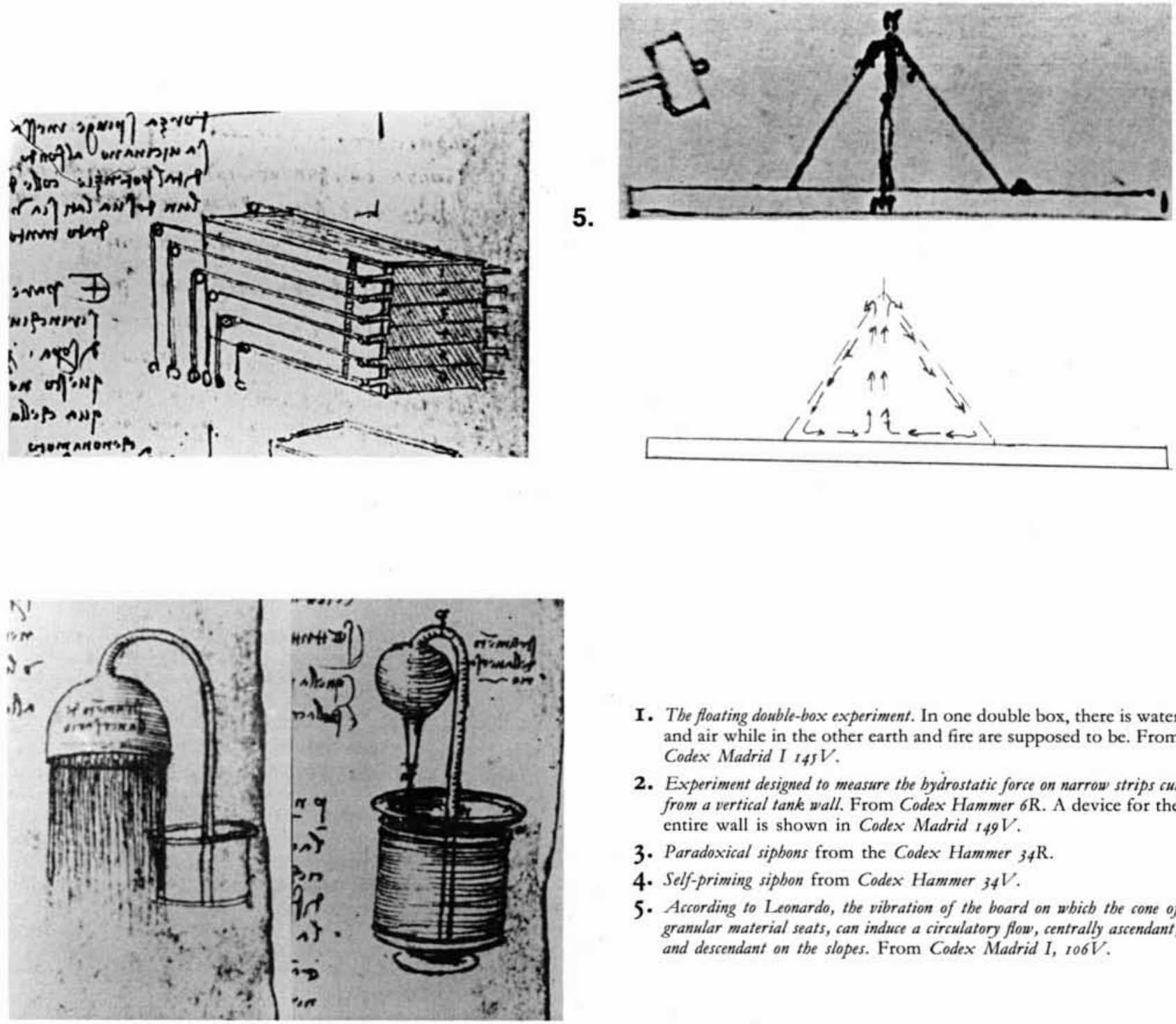

I. The floating double-box experiment. In one double box, there is water and air while in the other earth and fire are supposed to be. From Codex Madrid I $145 \mathrm{~V}$.

2. Experiment designed to measure the bydrostatic force on narrow strips cut from a vertical tane wall. From Codex Hammer $6 \mathrm{R}$. A device for the entire wall is shown in Codex Madrid ${ }_{149} \mathrm{~V}$.

3. Paradoxical sipbons from the Codex Hammer $34 \mathrm{R}$.

4. Self-priming sipbon from Codex Hammer $34 \mathrm{~V}$.

5. According to Leonardo, the vibration of the board on which the cone of granular material seats, can induce a circulatory flow, centrally ascendant, and descendant on the slopes. From Codex Madrid I, 106V. 
hydrostatics, I will include the experiment of the floating double box [Macagno 1982], which is crucial in regard to the old physics which Leonardo had difficulties in putting to use. Also in hydrostatics, the designs of experimental determinations of forces and pressure distribution on the walls of a tank are remarkable. In the area of flow phenomena, I will include Leonardo's studies of impingement of jets, perforation of nappes by jets, siphon flow, and flow of granular materials. The criterion for the above selection is that each experiment illustrates an important facet of the experimentalist's work in Leonardo, including both successes and failures. The core of the paper is, however, an extraordinarily meaningful experiment, which contains enough data for a quantitative analysis.

\section{Experiments revisited}

If a cylindrical container with two compartments encloses water in one and air in the other, and it has a relatively low ratio of height to diameter, it may float stably in two positions. In figure $I$, we see Leonardo's sketch for the case with water on top. This experiment could have been devised to investigate the stability of floating bodies like ships, which would surely be the first interpretation if a hydraulician or a naval architect reads the description or examines the corresponding drawings. However, 1 was not able to find any trace of an understanding of hydrostatic stability in the rest of Leonardo's notebooks. I consider now wrong my first conclusion about the significance of this experiment. By rereading his specific comments, and mainly by putting together many other notes on air and water in the midst and outside their spheres, I have come to the conclusion that what Leonardo was looking at here was an experimental reality surely paradoxical to him, and surely also to any of this contemporaries imbued with the physics of their times (both Greek and Medieval physics). In this experiment, they could see that it was possible to put water and air outside their spheres, and, in spite of the device seemingly being free to turn over, it would not do so. As long as the ratio height over diameter is somewhat below a critical value, one can disturb the double box trying to help the overturn but it will not happen easily, and of course, not spontaneously. It must have been very puzzling indeed to see that there could be portions of water outside the water sphere, which would not "desire " to return to their home. This experiment showed something that Leonardo also knew happened in relative equilibrium when a cylindrical container partly filled with water is rotated. Within the traditional physics he had inherited, there was a truly paradoxical violation of the principle that water and air, if free, would always go back to their respective spheres. Nowadays we know more about dynamics, and we know what maintains the fluids avay from their spheres, it is clearly within the laws of Newtonian mechanics. But to Leonardo such an explanation was completely out of the question; and we cannot imagine how he could have found one. What he was able to establish was that there were crucial, simple experiments that disproved long accepted tenets of the received knowledge of physics.

Leonardo's studies of hydrostatic forces and pressures are interesting because his approach is so different from that of Archimedes, who made a magnificent contribution but confined within the domain of an axiomatic statics [Dijksterhuis 1957, Arredi 1942-43]. Leonardo erred seriously regarding hydrostatic forces as illustrated by his notion that the sum of the forces on the walls and bottom of a cubic tank would be equal to the weight of the water [Macagno 1982]. This mistake was perhaps mitigated by the experiments he designed regarding the same forces. In contrast, his notions about pressure were much closer to being correct. His approach was eminently experimental, and among the several experiments conceived to reveal knowledge about pressure, the cleverest is the one in which he divided the wall in horizontal strips as to allow measurements of what we may denote by $\Delta F$ (fig. 2).
By making equal all the areas $\Delta A$ of the strips, $\Delta F$ comes very close to revealing the pressure distribution. That Leonardo did actually realize this experimental arrangement, and measured the forces, is doubtful, but even if this, and other experiments, were only " gedanken Experimente ", they would still be enough to ensure him a place in the history of hydrostatics.

Perhaps also in the category of thought experiments [Kuhn ${ }_{1977]}$ are those in which Leonardo proposes to " the adversary " the consideration of certain siphons which some of my students, just beginning their first course in fluid mechanics, thought could work. Those students were misled by an application of analysis of equilibrium and impending motion borrowed from the mechanics of solids. Some of those students argued on the basis that there was so much weight on the delivery side of the siphon and so little in the other side that it had to work. Two such siphons are illustrated in figure 3 (See others in the Codex Atlanticus, Macagno 1986b). It is perhaps pertinent here to mention another experiment that may have puzzled Leonardo very much, knowing that he considered the effects of what we call now surface tension to be very strange, almost mysterious. He knew that the siphon illustrated in figure 4 actually works as a self-priming device ; one can repeat it very easily with a piece of dry felt which is placed around the rim of the vessel as shown in Leonardo's sketch; the spontaneous capillary rise primes the siphon.

There are a number of experiments of flow of granular material in Leonardo's notebooks. One that is revealing of its wide interest is that of the circulation in a cone of granular material which has been formed over a board that is then carefully subjected to vibration (fig. s). Leonardo experimented with granular materials in different ways; for example, he let them come out of an orifice at the bottom of a hopper and form cones. Leonardo believed that the cone shape should follow some excessively simple geometric law (see, e.g. CA $238 \mathrm{R}$ ), but what is interesting here is not so much this phase of the experiment as the second one, sketched in figure s. Leonardo subjected the board, on which the cones were formed, to vibrations; he described the ensuing internal flow very well, but we do not know what means he used to visualize such flow. There is an important detail in that Leonardo formed the cones in one particular case by tapping on a board which was covered initially with a presumably uniform layer of granular material ; this resulted in the formation of cones and it was for such cones, after becoming stable, that he wrote the following comment:

If you would bit the board covered with granular material, it will gatber in a number of monticles. In such monticles, the grains will flow down towards the base from the vertex of the cone. There, they re-enter underneath moving towards the middle and up to fall again from the top of sucb monticle. In this way, the material will circulate along the right triangle amn as many times as the percussion continues. (CMI $126 \mathrm{~V}$ )

Il have repeated this experiment with granular materials of different colors to visualize the motion and found Leonardo's description of the circulation to be correct [Macagno 1982].

The significance of this and similar studies of flow of granular material is two-fold, because they seem to be the first studies of what we call now soil mechanics, and perhaps still more interestingly, because they were constantly linked via analogy with the flow of water. In some cases, as when analyzing thin jets, Leonardo was correct in his assumptions; we still use, as a good approximation, a similar approach to study thin jets when we take for granted that the path of a single particle tells what all those in a jet will do. But when trying to determine the flow of water towards and orifice in the bottom of a tank, in spite of a cleverly conceived experiment described below, he erred due to effects of rotation in the water that escaped his powers of observation [Macagno 1982]. The experiment, however, is well conceived to investigate the flow of granular material as one can deduce from the description in Codex Atlanticus $465 \mathrm{R}$. After pointing out 


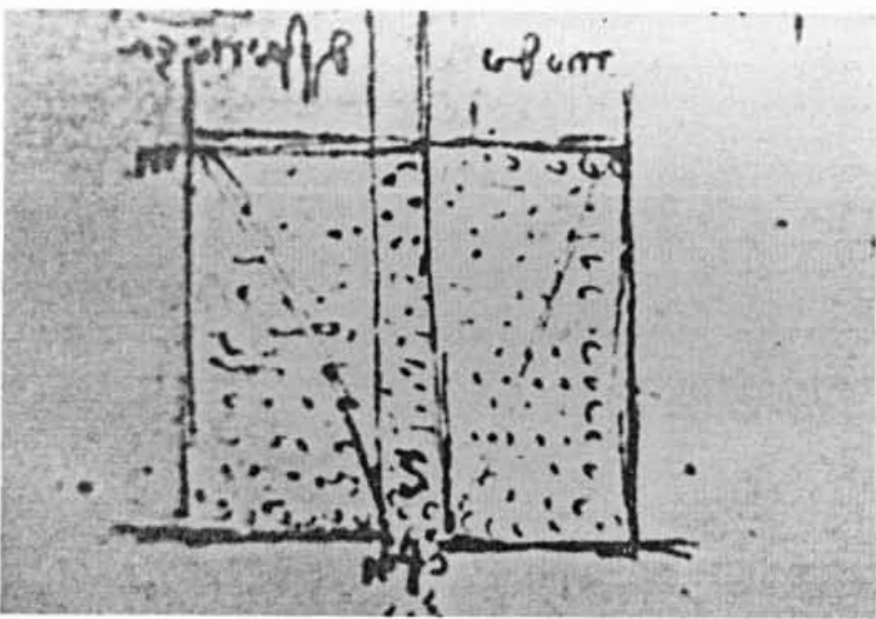

6.

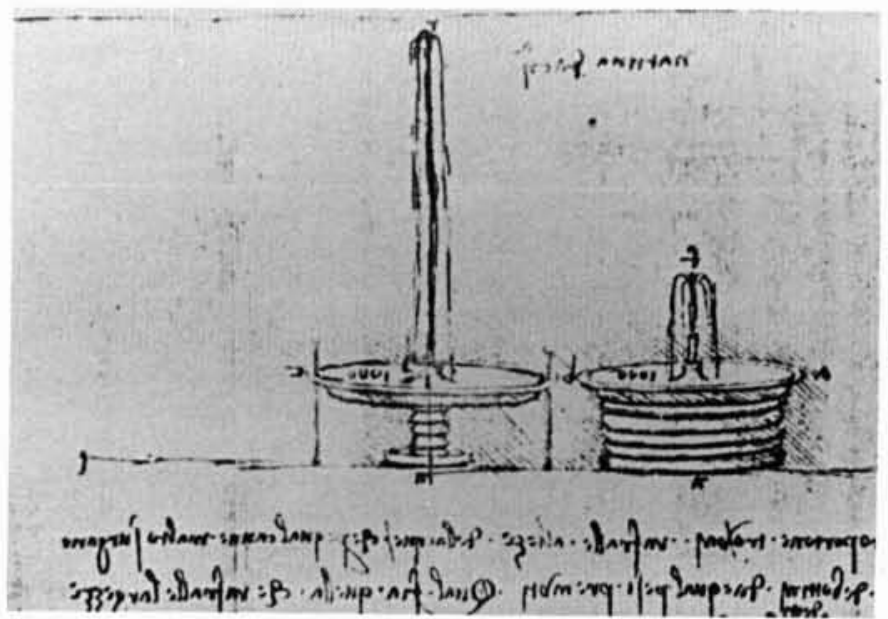

9.

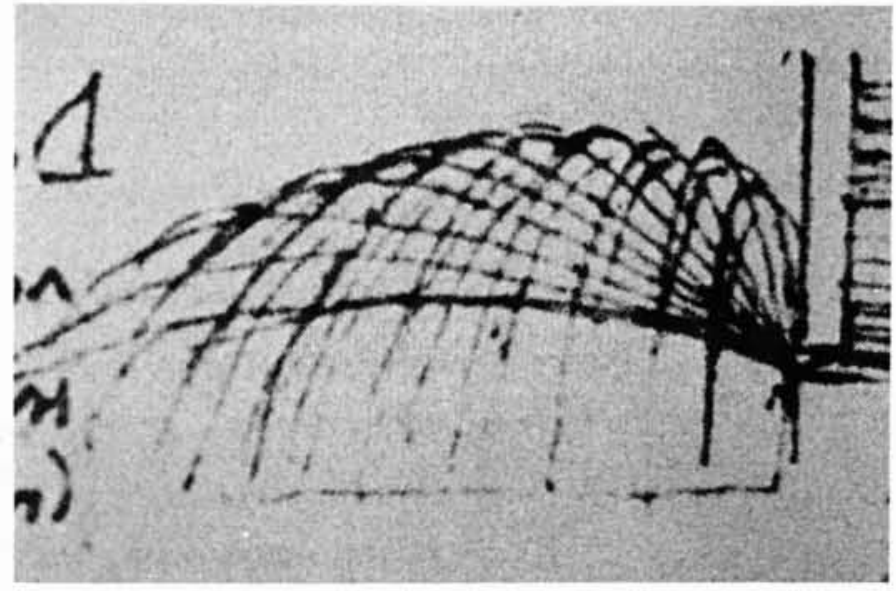

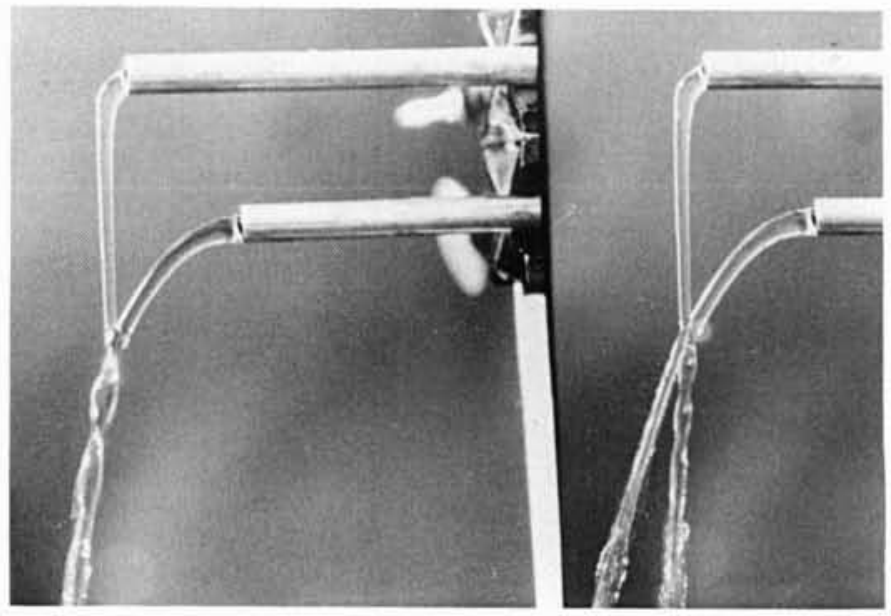

7.

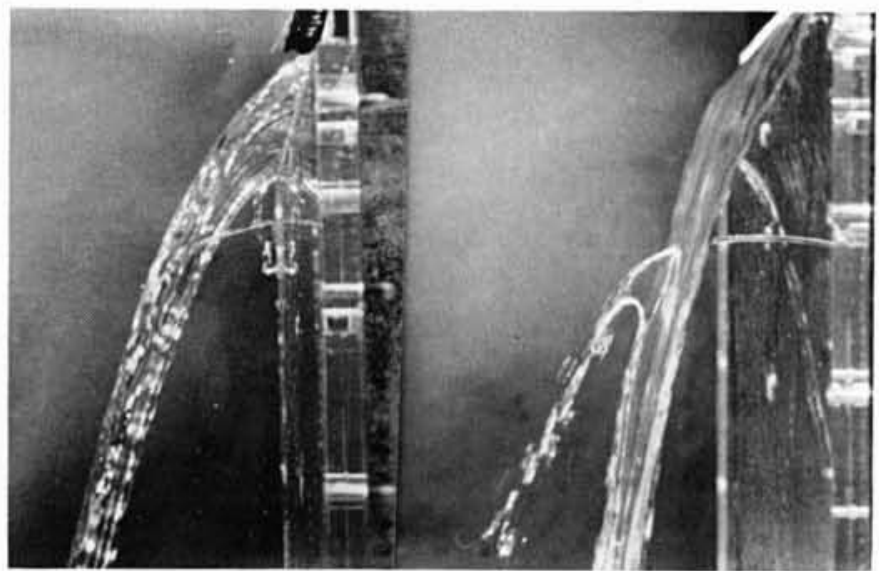

8.

6. Attemps at modelling flow of water towards a bottom orifice by means of granular materials of different colors. From Codex Atlanticus $467 R$.

7. Experiments with impinging jets. (Macagno at Hydromechanics Laboratory Karlsruhe University, 1975).

8. Experiments on interactions of jets and nappes. (Macagno at Hydromechanics Laboratory Karlsruhe University, 1977 ).

9. Devices sometimes described as table-fountains, but also used to discuss the relation between properties of jets and the pressure inside the bellows due to the weights acting upon them. From Codex Madrid I $124 \mathrm{~V}$.

IO. Family of jets showing the effect of resistance. Note that effect on vertical and nearly vertical jets seems to be emphasized. From Ms F, Institut de France, $16 \mathrm{~V}$.

10. 
at some differences between the flow of water and granular material from a tank with a bottom orifice, Leonardo describes an experiment (fig. 6) with seeds which deserves quotation in full :

\section{Method of experimenting}

Vessel with gramular material and orifice in the bottom, with the letters $\boldsymbol{m}-\boldsymbol{s}-n f$ :

To see experimentally which millet will be the one that comes out through the orifice in the bottom of the vessel, take a piece of thin paper and form a tube around a cane of uniform diameter and glue the ends. Then take away the cane and close the lower end (of the tube) and then fill the tube with black millet. Then put this tube close the orifice of the vessel so that the closed end coincides with it. Then fill the vessel with white millet. Once this is done, remove the tube without removing the stopper that was used to close it. In this way, you bave surrounded the black millet with white millet. Then open the orifice completely and quickly, and observe the descent of the millet to see whether it is black or white, and in what proportion, and you will be able to determine which millet comes out first, the black millet which is located vertically above the orifice or the white millet which is more remote. But I have some doubts that when the black millet is close to the last. i.e., it will be low and the white millet will be with its slopes bigh as shown in - $\boldsymbol{m} \boldsymbol{n}$ - white millet - and $\boldsymbol{S} \boldsymbol{f}$ - black millet that the white millet will not fall down before the black millet. (CA $465 \mathrm{R}$ )

This is an experiment that is really easy to repeat, and I have done it. 1 believe that the reader can do it also and would learn more in that way than if 1 would describe my own experience. The same container can be used for water, and in such a case, 1 recommend to try two variants : one without any initial circulation of the water, and one with circulation. Only by experimenting oneself can one really begin to understand what Leonardo's experiments mean, and how much one can learn even in cases in which no measurement is performed [Macagno 1982$]$.

The impingement of fluid jets is only a part of a wider area of study that one finds in several notebooks and codices of Leonardo. Perforation of water nappes is an extension of such a topic, and I will comment on both phenomena here. We find evidence in the technical drawings of Leonardo, that he was interested in jets coming out from two bellows (which were apparently used for both liquids and gases) that came together, perhaps in order to mix different fluids [Codex Atlanticus $165 \mathrm{R}$, Macagno 1989a]. Of course, in many fluvial problems two streams come together and interact sometimes strongly, sometimes weakly. There is also the intersection of diagonal stationary waves, which Leonardo, for some time, mistakenly assumed to be currents, instead of moving forms. The impingement of two jets was illustrated repeatedly by Leonardo with the two solutions of bouncing and merging. At some points, Leonardo seems to indicate that two fluid jets could go across each other as two beams of light.

I went through the experience of asking some of my colleagues if they believed that two jets could come together and bounce back (without mentioning Leonardo, of course); sometimes 1 was told that 1 should know better ! But 1 decided to experiment, and after enough variations of parameters I was able to obtain jets that would either merge or separate after a brief encounter (fig. 7). A similar experience characterized my laboratory study of perforation of nappes by jets (fig. 8); one could obtain one or the other with more ease than in the case of impingements of jets. Only once, in a water fountain, have 1 ever been able to see as a natural occurrence of this phenomenon in my many years of watching flows that happen around me. There is a possibility that Leonardo had a similar chance; we will never know, but the fact is that in many places in his notes we find descriptions of these experimental results. Some people want to attribute all of Leonardo's findings to good chance, but then it would seem that Leonardo was lucky almost every day of his life!
To close this brief summary of some of the jets experiments by Lconardo, let us look at those experiments in which he studies jets in order to learn what happens to the pressure in the containers from which the jets issue [Macagno $1985 \mathrm{a}$, $1987 \mathrm{a}, \mathrm{b}]$. The experiments of this kind described in the Codex Madrid (and also in CA ${ }_{6} \mathrm{R}$ ) are very revealing (fig. 9). Leonardo knew about jets that are directed vertically upwards, not only in connection with what Torricelli was going to investigate brilliantly later, but also from a more difficult point of view ; within a certain range upwardly directed jets fall upon themselves, thus strongly hindering their reach. Many designers of fountains take advantage of this effect. Knowledge about the possible reduced reach of vertical and almost vertical jets is reflected in the family of jets in the Ms F (fig. 10) which suggest a (not drawn) envelope that peaks not for the vertical jet (which is shown with a reduced reach) but for a jet with some initial inclination that ensures free upward flow [Macagno 1987a]. To think of this experiment as revealing Leonardo's concept of a family of curves is all right, but the most important aspect is that of the knowledge of dissipation of energy that makes evident. The notion of dissipation of energy can be found in several places in Leonardo's manuscripts. This is another example of paradox in the knowledge of fluid mechanics that Leonardo attained : he seems to have seen more clearly the notion of dissipation of energy than that of energy itself.

\section{Leonardian notions about resistance to motion}

In many instances, Leonardo da Vinci demonstrated having a direct knowledge of resistance to motion as well as a grasp of the notion, so familiar to us today, of the ever present dissipation of energy in mechanical systems. Leonardo expressed his notions about the effect of resistance in connection with the height reached by a ball or a projectile after impact on the ground, or about the height reached by water under the action of another water coming down, or by the action of descending bodies used as loads on vertical bellows. He studied the vertical reach of jets, as well as their horizontal reach. He knew the difference between the limitations to vertical reach of an upwardly launched projectile and that of a water jet shooting vertically upward [see, e.g., Codex Madrid $[124 \mathrm{~V}]$. We must take into account that when Leonardo was trying to explain some of his observations, he would frequently resort to the physics that he had somehow learned from readings or conversations with learned people. Thus we find discussions about resistance tainted with reasons that show such an influence. For instance, in spite of his experimental knowledge about friction, Leonardo would attribute the asymmetry of the path of a projectile with both ascending and descending branches to the "desire of the projectile to return to earth " after reaching the maximum height [CM $1_{14} \mathrm{R}$ ]. In this contribution, the case of the effect of resistance on a pendulum will be considered following Leonardo's analysis. It is a passage that offers much more insight than many others on similar topics. But before, we will examine some additional related questions.

As one examines the drawings in the notebooks of Leonardo, it is easy to develop the feeling that he believed in perpetual motion, but in fact he condemned in very harsh terms those who perpetually tried to make machines that would work for ever, or even produce energy well above that which was provided to them [Macagno 1982]. Precisely from the Codex Madrid, we have a passage concerning those pursuing the chimera of perpetual motion. About them Leonardo wrote:

Among the many superfluous, impossible credulities of mankind, I bave found the search for continual motion, also called by some the perpetual wheel. This bas lasted for many centuries in a long search and experimentation at great expenses. And it has occupied most of the 


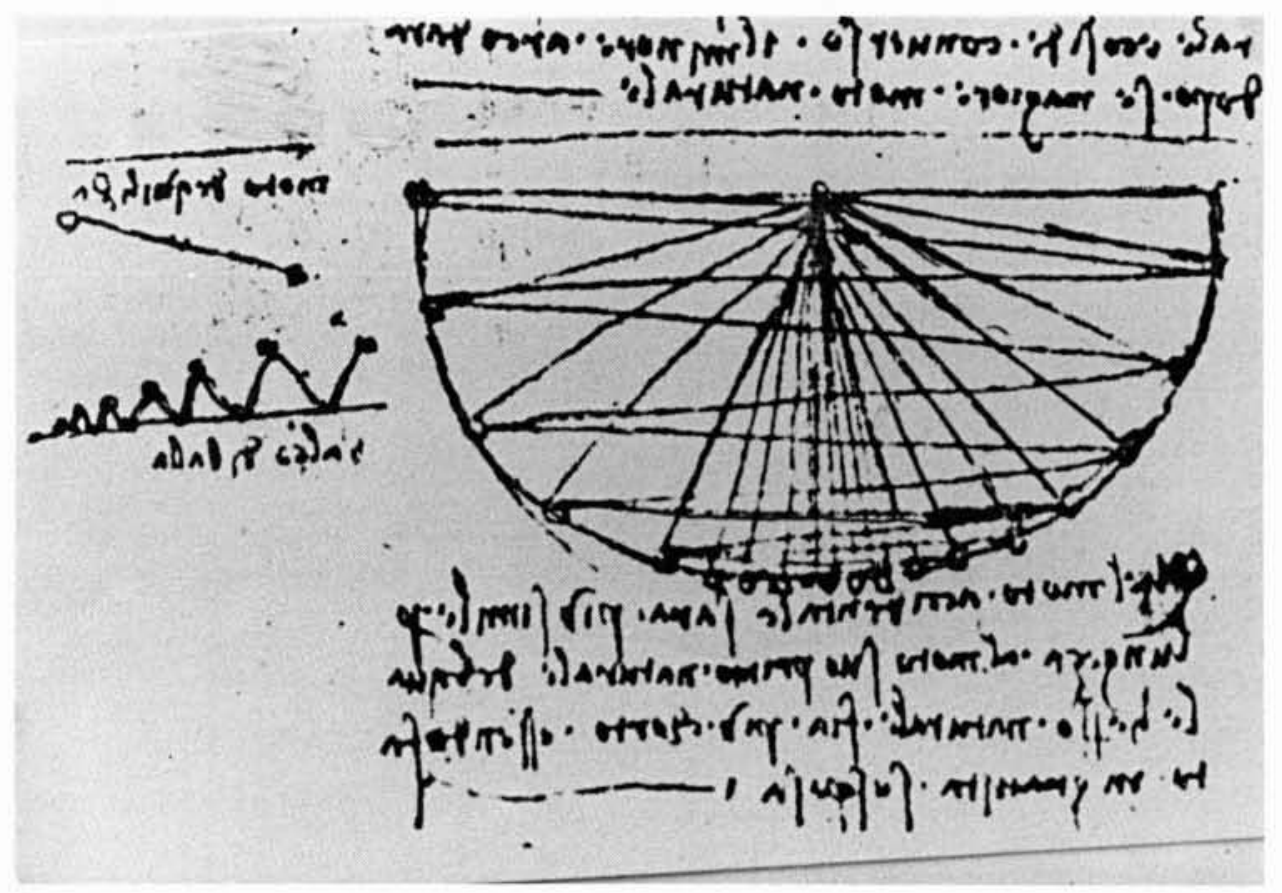

II. Decay of oscillations. Drawings from the Codex Madrid $I_{147} \mathrm{R}$. One of the small sketches illustrates the decaying height attained by a bouncing ball. The large drawing is presumably a record of the observed decay of oscillations of a pendulum.

men who find delight in bydraulic and war machines as well as otber clever devices. And finally it has always bappened to them what bappens to the alchemists, that for a small detail the whole thing fails. Now, I intend to be charitable to that band of researchers: to grant them a period of quied in their endeavors as long as it takes me to complete this little work of mine. Moreover, their promises to others will bave the desired end, and they will not bave to be running away due to the impossible things they bave promised to the princes and rulers of peoples. I remember to bave seen many people of different countries driven to the city to $V$ enice by their puerile credulity and great bopes of moneymaking by implanting mills in stagnant water. As they could not, after great expenses, start such macbines, they were compelled to set themselves in bastily motion away from such region.

On the other hand, in passages, that are less known perhaps because what concerns fluid mechanics has been largely ignored or neglected by historians of science, Leonardo was constantly concerned with resistance to motion, and the corresponding dissipation of energy. Of course, in his terminology there could not be room for what we only in rather recent times have designated as dissipation of energy, or entropy, and also for the concept of energy, but he undoubtedly had a grasp of such notions in an incipient form. Leonardo appears in many instances interested in perpetual machines, and one is sometimes wondering if he was completely free from this spell. Personally, I do not find strange that one would want to study proposed perpetual machines and examine the arguments of their inventors. It is sometimes quite an intellectual challenge to demonstrate where is the mistake in a concrete, direct way, rather than just discarding the particular example with arguments based on general principles of modern physics.
In modern analytical mechanics, we consider many times the behavior of frictionless systems which provide many theoretical examples of continual motion ; for instance a wheel free to rotate on its axle, if we assume that it is completely free from friction, will continue to rotate forever, in the same way that a body will continue in motion for ever under the conditions of the first of the Newtonian laws of mechanics. The same would be true of a pendulum once set in motion with a given amplitude. This is not the same as the idea of perpetual machines, which not only would continue to move but would also yield a constant rate of work without receiving a corresponding amount of energy.

Leonardo's notions about dissipation of energy are found in many of his notes, and are evident in a number of his drawings. For instance, in drawings of the path of a projectile, or in drawings of jets, the curves he drew show what we call today an asymptotic behavior, which we know is what happens if resistance is taken into account. This feature is today illustrated not only in books on ballistics, but even in standard textbooks of engineering mechanics. It is easy to show that a body experiencing linear resistance has a path with a vertical asymptote located at a horizontal distance easily expressed by the ratio $U / k$; here $U$ is the initial horizontal velocity, and $k$ the resistance coefficient in $\mathrm{d} u / \mathrm{d} t=-k u$, the differential equation of motion for the $x$-component. Somewhat more involved is the analysis for a resistance proportional to the square of the velocity, and even more for a resistance which would take into account present knowledge of fluid mechanics about resistive forces in fluids [See, e.g., Synge and Griffith 1949], but the vertical asymptote is found in all cases. 


\section{Leonardo on decay of oscillations}

In the Codex Madrid, CMI ${ }_{147} \mathrm{R}$, we find two examples of oscillatory motions of diminishing amplitude. In one, a small sketch illustrates the successive bouncings of a ball (balzo di balla) which initially has hit the ground at an angle; in the other, the decay of the oscillations of a pendulum (gravita sospesa) are shown in a better drawing (fig. II). Leonardo's brief comment for this figure is :

That accidental motion will be more like its initial natural motion in path length in the proportion that is shorter, when it is accomplished as a suspended weight. (CMI $\left.{ }_{14} 7 \mathrm{R}\right)$

In a few words we have here a description of an important feature that was perceived by Leonardo; namely that in his pendulum there was stronger decay for large amplitudes than for small ones. But the use of the terms "natural motion " and "accidental motion" to describe the descending and the ascending part of the pendulum path should also be noted, because we know that Leonardo used terminology and also concepts of the old physics, presumably for lack of anything better. I am convinced that we also fail to escape the use of received terms and concepts when we want to give profound explanation of some of our own empirical findings, with the difference being that we are somewhat better armed in theoretical and mathematical terminology than Leonardo was.

Leonardo's data for his pendulum were probably originally recorded in a rather direct manner as he watched the oscillations. What we have is a drawing in which Leonardo marked the successive positions of reversal of the motion of the pendulum. We do not know how he transferred the results to a smaller scale (fig. $I I$ ). I believe that Leonardo was not familiar with the measurement of angles in degrees. I have considered the hypothesis that he could have approached the problem in the manner of an artist capable of depicting a moving body in several positions with reasonable accuracy. Perhaps he used a semi-circle (not a protractor) made of metal or wood and simply proceeded to mark positions on it, or maybe, he used the shadow of the pendulum on a piece of cloth. We will probably never know how he constructed this graphical record, but the data from it appear as amazingly consistent when represented in a Cartesian diagram.

\section{Analysis of Leonardo's data}

1 have enlarged Leonardo's drawing and had the angles read by different persons, and taken an average for each. I have considered these readings as data originated by Leonardo da Vinci, and subjected them to careful study. Usually, I would have considered exploring this matter by means of the laboratory method, and mounted different pendulums with which to experiment myself until finding data like those of Leonardo. Fortunately, however, similar work had already been done by some students in my course of Experimental Methods in Fluid Mechanics at the University of lowa. My students experimented with pendulums moving through air and water. Therefore, 1 knew that the search for a physical pendulum that would behave like that of Leonardo could be a frustating trial-and-error task. On the other hand, I knew that the analysis of the pendulums used by my students was satisfactorily achieved by applying a simplified calculation, based on modern knowledge of resistance to motion through a fluid. It is quite likely that Leonardo's pendulum was moving through air and not through other fluids, according to some exploratory tests that I carried out myself anyway. Thus, I decided to focus on an analytical rather than an experimental methodology in my study of the data.

To analyze the data from the Codex Madrid I, I have made several assumptions, which are inspired in those used by my students in the above mentioned work.
1. The pendulum was surrounded by otherwise still air.

2. The length and shape were such that the relative flow was turbulent (square law of resistance) for large amplitudes, and shifted to laminar (resistance proportional to the velocity) for small amplitudes. Since we know nothing about the shape of the pendulum, it would seem unwarranted to try a more complex scheme for the resistance law.

3. The dry-friction resistance was negligible. This is based on knowing that Leonardo knew how to reduce friction to very small values [Reti 1980 ].

4. One can use finite differences, and take as time interval the one half period of the oscillations, and use as velocity the average over that time.

5. The duration of the period can be calculated by determining the period from the already classical formula of the pendulum with large-amplitude oscillations [Synge \& Griffith 1949]. The available expression is for zero resistance, but we will use the knowledge that in damped oscillations, the resistance must be rather large to have an important influence on the period.

6. We will also assume, since we are interested in establishing whether the trend of Leonardo's data is approximately correct and not concerned with the accuracy of his individual measurements, that we do not need to match absolute values but only relative values of the decay of the oscillations. This includes a variation of parameters in search for the assumed transition from turbulent to laminar flow.

\section{Approximate expressions}

In order to establish the approximate formulas, we begin by examining the exact differential and integral equations available for the study of this problem. The momentum equation for the pendulum of mass $m$ and length $L$ (fig. 12), including a general resistance force $R$, is

$$
m(\mathrm{~d} v / \mathrm{d} t)=-m g \sin \theta-\mathrm{R}
$$

Because $m$ performs a circular motion, we can express the velocity $v$ as $L(\mathrm{~d} \theta / \mathrm{d} t)$. If we do this and multiply the above equation by $v \mathrm{~d} t=\mathrm{d} s=L \mathrm{~d} \theta$, we obtain the following equation

$$
m d\left(V^{2} / 2\right)=-m g \mathrm{~L} \sin \theta \mathrm{d} \theta-R L \mathrm{~d} \theta
$$

which after integration yields

$$
\begin{aligned}
& m\left(V^{\left.m^{2} / 2\right)-m g} \cos \theta^{\prime \prime}=\right. \\
& =M\left(V^{\prime 2} / 2\right)-m g \cos \theta^{\prime}-\int_{\theta^{\prime}}^{\theta^{*}} R L \mathrm{~d} \theta .
\end{aligned}
$$

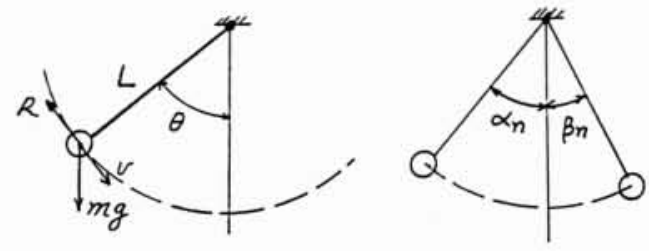

12. Two definition sketches for the calculations of the decay of oscillations of a pendulum described in the text. 
This is to be interpreted as follows : the sum of kinetic and potential energy at one position is equal to the value at a preceding position minus the energy dissipated by the resistance to motion in between the two positions. For a given pendulum and a given fluid, the resistance can be assumed to depend on the values of $\theta$ and of $\mathrm{d} \theta / \mathrm{d} t$. For a fluid of high density we should include the acceleration as an additional variable; i.e., we should take into account the added mass effect. But for a pendulum which is relatively heavy moving through air this would surely be an unjustified refinement.

We will be using finite differences with rather large time intervals, and we need to have some estimate of the errors involved. We have two cases to consider : that of quadraticresistance law, and that of linear-resistance law. We will use, however, a single expression with an exponent $m$ which can take one value or the other.

$$
\mathrm{R}=k V^{m}=k L^{m}(\mathrm{~d} \theta / \mathrm{d} t)^{\mathrm{m}}
$$

we replace $\mathrm{d} \theta / \mathrm{d} t$ at any step by $\left(\alpha_{n}+\beta_{n}\right) / T_{n}$, where $T_{n}$ is the time for the pendulum to sweep the angle $\alpha_{n}+\beta_{n}$ (fig. 12). We now have

$$
R=k L^{m}\left(\alpha_{n}+\beta_{n}\right) / T_{n}^{m} .
$$

This may seem to be a very crude approximation, but experience with approximate calculations can teach that one cannot easily conjecture the relative importance of the error introduced without experimenting with the calculation scheme selected. One should try very simple schemes and use them if some testing reveals that they prove to be satisfactory. 1 have taken a linear oscillator of behavior similar to that of Leonardo but with linear resistance, for which one can calculate mathematically the decay of the oscillations, and performed approximate calculations with time intervals equal to half the period of the pendulum. The results gave me confidence in my approximations.

The equation used to compute amplitudes for our theoretical pendulum is the following

$$
\cos \alpha_{n}-\cos \beta_{n}=C\left(\alpha_{n}+\beta_{n}\right)^{m} / T_{n}^{m}
$$

which is derived from the expressions given above. This formula is simpler because at the extreme positions in each half oscillation, the kinetic energy vanishes. The angles in this formula are those at the beginning and at the end of each half period $T ; C$ is a constant ; because we consider a dissipative force, it seems necessary to introduce values of $T$ somewhat larger than those of a pendulum without resistance, but some calculations have shown that the correction would be too small compared with other errors. A calculation with an extreme decay from $90^{\circ}$ to about $50^{\circ}$ has shown that the change in the period is less than $2 \%$.

In figure $\mathrm{I}_{3}$, I show the comparison between the data read from Leonardo's drawing and the calculations using modern procedures (points for Leonardo's data, and crosses for my calculations). The point for $n=8$ was left out by Leonardo and therefore is also missing in figure 13. This figure shows general agreement and some local deviations. These deviations can be diminished at one end or the other but not at both. An intermediate solution has beed adopted. We should take into account that we are not examining data from a modern laboratory, but data that were undoubtedly based on rather crude procedures of which nothing is known.

This experiment is remarkable in several aspects. It is significant that Leonardo appears to have been able to observe quantitatively, and not only qualitatively, a fact that may be considered by many as a great feat. It is, however, the choice of the decay of oscillations as an iterative evidence of dissipation of energy at each step that must be emphasized. We should also note that this is a much easier observation than that of resistance for projectiles or for falling bodies with which Leonardo was also familiar. It is also much easier to observe the effect to resistance in the pendulum than in water jets. The decay of the bouncing heights of a ball (depicted in fig. II) is also an interesting experiment, although not so easy to perform.

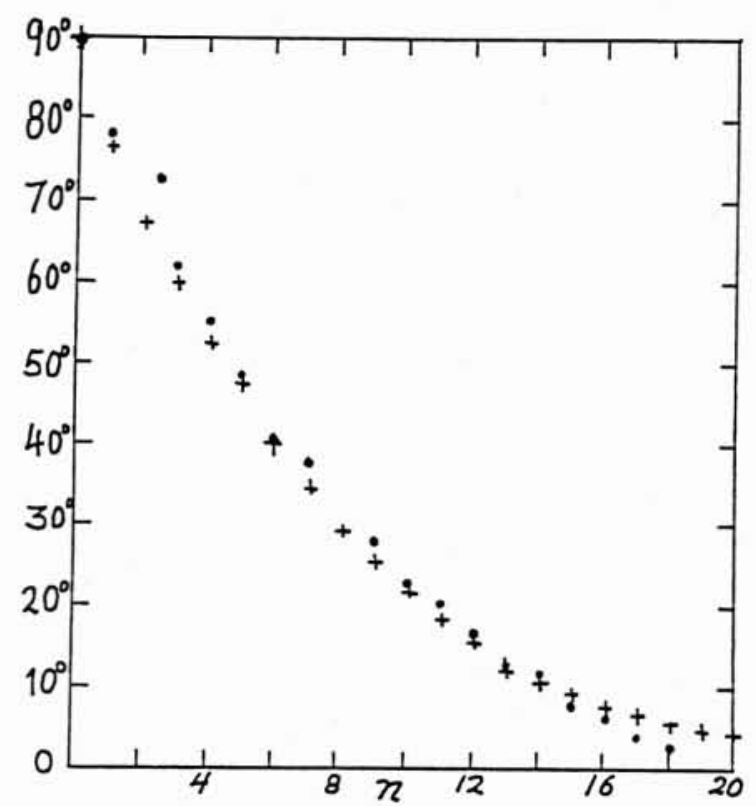

13. Comparison of Leonardo's data and the results of calculations by the author. Leonardo's data are represented by a dot, while the calculated values are plotted as crosses. 


\section{Conclusion}

As one examines more and more experiments described by Leonardo, it becomes apparent that a number of them are of a fundamental nature. The simple experiment of the decay of the oscillations of a pendulum is of significance in the analysis of Leonardo's studies of mechanics and fluid mechanics because it offers a solid justification to the many passages in his notebooks in which we find notions and concepts about resistance, and therefore about dissipation of energy. His experiment offers a way of exploring fluid resistance in a rather simple experimental arrangement, which visualizes repetitively the continual decay of the amplitude. All of this must have played a role resulting in a strong conviction which we see manifest in the harsh condemnation by Leonardo of those around him seeking to accomplish perpetual motion machines. Such condemnation is found in the same notebook in which he registered his notes on the decay of the oscillations in different phenomena. It may seem paradoxical that Leonardo did not pay attention (at least in the extant documents) to the duration of the oscillations of a pendulum depending on its length, or the more difficult-to-observe effect due to the ampli- tude of the oscillations, and instead used the pendulum as an experimental device to study the effect of resistance to motion.

From the point of view of fluid mechanics, the manuscripts of Leonardo contain a treasure that has not yet been fully explored. This contribution to a synthesis of such material has been focused on a group of remarkable fundamental experiments, some of which must have convinced Leonardo that he could not rely on the received knowledge of physics. That he, singlehandedly, did so much to understand the physical world around him is his major accomplishment. We will never know whether he had full awareness of how far he had advanced into new unknown territory that was only to be explored in centuries following his own. But in the Codex Madrid we have a note that reveals his awareness that he had ventured into a new world much more fascinating, I think, than the one explored by his contemporary Christopher Columbus, of whose accomplishments not a single note seems to have been made by Leonardo da Vinci. These two great men seem to have lived oblivious one from the other.

\section{References}

ARRIDI F. (1942-43), - Le origini dell'idrostatica. L'Acqua, fasc. 3, 7. 11,12 of 1942 ; fasc. 2 , 5 of 1943.

BIRKHOF (j. (1950), - Hydrodynamics. A Study in Logic, Fact. and Similitude. Princeton University Press for the University of Cincinnati.

Dijksterutus E.J. (1957). - Archimedes. The Humanitics Press, New York (There is a paperback printing by Princeton University, $1987)$.

GiscomelLt R. (1936). Gli scritti di Leonardo da V inci sul volo. Bardi, Roma.

Gombrich E.H. (1966). Norm and Form. Studies in the $\Lambda \mathrm{rt}$ of the Renaissance. Phaidon Press, London.

KuHN T.S. (1977). The Eissential Tension. The University of Chicago, Chicago and London (See Chapter 10, A Function for Thought Experiments).

MACAGNO E. (1953). Análisis cualitativo del movimiento de los liquidos. Acta Cryana de Ingenieria. vol. $1, \mathrm{n}^{\circ} 4$.

Macagno E. (1982). - La meccanica dei fluidi nei Codici di Madrid, Scientia, Special volume. Milano, Italy (English version available).

Macagno E. (1985a). Hidrostática Vinciana en el Códice Hammer. Anales de la Unirersidad de Cbile, Quinta serie, $n^{\circ} 8$.

MACAgNo E. (1985b). - Leonardo's Methodology in his Fluid Mechanical Investigations, Proceedings International Symposium on Modelling and Turbulence, Paper K 3, IIHR, The University of lowa, lowa City, lowa, USA.

MACAGNO E. (1986a). Analogies in Leonardo's Studies of Flow Phenomena. Studi V imciani. Centro Ricerche Leonardiane, Brescia, Italy.

Macagno E. (1986b), Leonardian Fluid mecbanics in the Codex Atlanticus A Survey. IIHR Monograph $n^{\circ}$ 100. The University of lowa, lowa City, IA, USA.
MACAgivo E. (1987a). - Lconardo da Vinci: Engineer and Scientist, in Hydraulics and Hydraulic Research, a Historical Rerien, ed. by G. Garbrecht, A.A. Balkema, Rotterdam (Expanded version of the Berlin lecture in 1985 ).

Macagvo E. (1987b), - La noción de presión en la mecánica de fluidos Vinciana, Raccolta V inciana. Fascicolo XXII, Milano, Castello Sforzesco.

MACAgNo E. (1989a). Leonardian Fluid mecbanics in the Codex Atlanticus. I-111. IIHR Monograph $\mathrm{n}^{\circ}$ 105. The University of lowa, lowa City, 1A, USA.

MACAgNo E. (1989). - Experimentation, Analogy and Paradox in Leonardo da Vinci. Raccolta V inciana, Fascicolo XXIII, Nilano.

MACAgio E. (1991). Lagrangian and Eulerian descriptions in the flow studies of Lconardo da Vinci (To be published in Raccolta Vinciana).

MACAGNO M. and MACAGNO E. (1975). Nonlinear Behavior of Line Vortices. The Pbysics of F/uids, vol, $18, \mathrm{n}^{\circ} 12$.

MARINONI A. (1954). I manoscriti di Leonardo da Vinci e le loro cdizioni. In Leonardo. Saggi e ricercbe. Roma.

PeDretTl C. (1985). Leonardo : il Codice Hammer ela Mappa di Imola presentati da Carlo Pedretti. Giunti Barbèra Editrice, Firenze (See figs. 12-13).

RETI L. (1975). The Madrid Codices. Commentary, vol. III, McGrawHill, New York.

RETI L. (1980). The Engincer, in Leonardo : the Imentor. McGrawHill, New York.

SYNGE J.L. \& GRIFFTH B.A. (1949). Principles of Mechanics. McGraw-Hill, New York.

Truespiti. C.A. (1967). Leonardo da Vinci, the Myths and the Reality. The Jobns Hopkins Magazine, spring 1967. 